\title{
Sevoflurane with remifentanil allows rapid tracheal intubation without neuromuscular blocking agents
}

\author{
[Le sévoflurane, additionné de rémifentanil, permet une intubation \\ endotrachéale rapide sans myorelaxant]
}

Hwan S. Joo MD FrCPC, ${ }^{*}$ William J. Perks BSc PHM, $†$ Susan E. Belo MD PhD FrCPC*

Purpose: After inhalational induction with sevoflurane, we compared the effects of adding remifentanil $\mid \mu g \cdot \mathrm{kg}^{-1}$ or remifentanil 2 $\mu \mathrm{g} \cdot \mathrm{kg}^{-1}$ on conditions for tracheal intubation without neuromuscular blocking agents.

Methods: Before anesthetic induction, all patients were given 0.2 mg of glycopyrrolate iv to counteract the bradycardic effects of remifentanil. Two minutes after inhalational induction with 8\% sevoflurane and $50 \%$ nitrous oxide, 56 female patients with normal airways scheduled for gynecologic surgery were randomized to receive remifentanil I or $2 \mu \mathrm{g} \cdot \mathrm{kg}^{-1}$ in a double-blind fashion. One minute later, laryngoscopy was initiated for tracheal intubation. Conditions for tracheal intubation and hemodynamic response to tracheal intubation were assessed.

Results: Tracheal intubation was successful in all patients. The incidence of post-intubation coughing was lower in the remifentanil 2 $\mu \mathrm{g} \cdot \mathrm{kg}^{-1}$ group compared to remifentanil | $\mu \mathrm{g} \cdot \mathrm{kg}^{-1}$ group (I $\%$ vs $39 \%, P<0.02$ ). Optimal intubation conditions were also higher in the remifentanil $2 \mu \mathrm{g}^{\mathrm{kg}} \mathrm{g}^{-1}$ group at $89 \%$ vs $54 \% \quad \rho<0.0 \mathrm{I}$ ). However, the higher dose of remifentanil also resulted in a greater decrease in mean arterial pressure $(P<0.05)$.

Conclusions: The addition of remifentanil after sevoflurane induction allows for rapid tracheal intubation without neuromuscular blocking agents. The higher dose of remifentanil results in improved conditions for tracheal intubation but also caused a greater decrease in mean arterial pressure. Tracheal intubation using sevoflurane and remifentanil may be an alternative to traditional tracheal intubation with neuromuscular blocking agents.

Objectif: Après l'induction de l'anesthésie par l'inhalation de sévoflurane, nous avons comparé les effets de l'ajout de $1 \mathrm{mg} \cdot \mathrm{kg}^{-1}$ ou de 2 $\mathrm{mg} \cdot \mathrm{kg}^{-1}$ de rémifentanil sur les conditions d'intubation endotrachéale sans myorelaxant.
Méthode : Avant l'induction anesthésique, toutes les patientes ont reçu 0,2 mg de glycopyrrolate iv pour neutraliser la bradycardie associée au rémifentanil. Deux minutes après l'inhalation de sévoflurane à $8 \%$ et de protoxyde d'azote à $50 \%$, 56 patientes faciles à intuber et devant subir une intervention gynécologique ont été réparties au hasard et ont reçu I ou $2 \mathrm{mg} \cdot \mathrm{kg}^{-1}$ de rémifentanil en double insu. Une minute plus tard, on a amorcé la laryngoscopie précédant l'intubation endotrachéale. Les conditions d'intubation et la réponse hémodynamique à l'intubation ont été évaluées.

Résultats : L'intubation endotrachéale a été réussie chez toutes les patientes. L'incidence de toux post-intubation a été plus faible avec la dose de $2 \mathrm{mg} \cdot \mathrm{kg}^{-1}$ de rémifentanil comparée à la dose de $1 \mathrm{mg} \cdot \mathrm{kg}^{-1}$ ( $11 \%$ vs $39 \%, P<0,02$ ). Les meilleures conditions d'intubation ont été observées aussi avec $2 \mathrm{mg} \cdot \mathrm{kg}^{-1}$ de rémifentanil, $89 \%$ vs $54 \%$ $(P<0,0$ I $)$. Cependant, la plus forte dose de rémifentanil a entrainé une plus importante baisse de la tension artérielle moyenne $(P<$ 0,05).

Conclusion : L'ajout de rémifentanil après l'induction avec l'inhalation de sévoflurane permet une intubation endotrachéale plus rapide sans recours au myorelaxant. La plus forte dose de rémifentanil testée a fourni de meilleures conditions d'intubation mais a provoqué une baisse plus marquée de la tension artérielle moyenne. L'intubation réalisée sous anesthésie combinant le sévoflurane et le rémifentanil peut remplacer l'intubation traditionnelle avec myorelaxant.

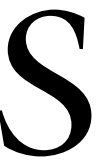

EVOFLURANE, a non-irritating inhalational anesthetic agent with low blood gas solubility, has been used for rapid induction of anesthesia. ${ }^{1}$ Proposed advantages of sevoflurane inhalational induction include lack of pain with drug injection, confirmation that the patient can be

From theDepartment of Anaesthesia* and the Department of Pharmacy, $†$ St. Michael's Hospital, University of Toronto, Toronto, Ontario, Canada.

Address correspondence to: Dr. Hwan Joo, Department of Anaesthesia, St. Michael's Hospital, 30 Bond Street, Toronto, Ontario

M5B 1W8, Canada. Phone: 416-864-5071; Fax: 416-864-6014; E-mail: hwanjoomd@yahoo.com

Reprints will not be available from the author.

Accepted for publication February 27, 2001.

Revision accepted April 2, 2001. 
ventilated as anesthesia is induced and the avoidance of neuromuscular blocking agents for tracheal intubation. However, induction time for adequate depth of anesthesia for tracheal intubation with sevoflurane is long when compared to traditional $i v$ induction with muscle relaxants. Muzi et al. found that time required to reach adequate depth of anesthesia for tracheal intubation, with $95 \%$ confidence level $\left(\mathrm{ED}_{95}\right)$, with sevoflurane was 5.7 min when $66 \%$ nitrous oxide was used and 7.7 min when $100 \%$ oxygen was used. ${ }^{2}$ It was our hypothesis that remifentanil, ${ }^{3}$ an opioid with quick onset and short half-life, used in conjunction with sevoflurane, would provide an adequate depth of anesthesia to allow tracheal intubation at three minutes. The present study was designed to investigate the effects of remifentanil $1 \mu \mathrm{gg} \cdot \mathrm{kg}^{-1}$ or remifentanil 2 $\mu \mathrm{g} \cdot \mathrm{kg}^{-1}$ on conditions for tracheal intubation follow ing sevoflurane induction.

\section{Methods}

After Institutional Ethics approval and informed consent, 56 ASA class I-II female patients between the ages of 18 to 65 scheduled for gynecologic surgery requiring general anesthesia and tracheal intubation were recruited. Exclusion criteria included allergies to the agents being used, risk of pulmonary aspiration, weight greater than $150 \%$ of ideal body weight and ASA classification III or higher.

Sample size calculation was performed on an a priori estimate of a clinically relevant difference of $35 \%$ (60\% of the patients in Group I (remifentanil 1 $\mu \mathrm{g} \cdot \mathrm{kg}^{-1}$ ) and $95 \%$ of the patients in Group II (remifentanil $2 \mu \mathrm{g} \cdot \mathrm{kg}^{-1}$ ) in optimal intubating conditions. For a power of 0.80 and an alpha error of $0.05,28$ patients per group were required. Patients were randomized to the different doses of remifentanil using a computer generated random number assignment. Both the patient and the study investigator were blinded to the dose of remifentanil. Remifentanil was prepared by the pharmacy and diluted to $10 \mathrm{~mL}$ total volume.

After placement of routine monitors (electrocardiogram, non-invasive blood pressure and pulse oximeter) and an $i v$ cannula, all patients received glycopyrrolate $0.2 \mathrm{mg} i v$ as an antisialogue and as prophylaxis against bradycardia. Inhalational anesthetic induction commenced with an anesthetic circuit primed with $8 \%$ sevoflurane in $50 \%$ nitrous oxide and $50 \%$ oxygen ( 3 lpm $\mathrm{N}_{2} 0: 3 \mathrm{lpm} \mathrm{O}_{2}$ ). Anesthesia was induced using the three breath vital capacity technique ${ }^{2}$ with a two-litre reservoir bag and a Datex AS/3 Anesthetic Delivery Unit. After confirmation of loss of lid lash reflex, ventilation was assisted with positive pressure ventilation to keep end tidal $\mathrm{CO}_{2}$ at a physiologic level between
$30-35 \mathrm{mmHg}$. Two minutes after induction of anesthesia, the $\mathrm{N}_{2} \mathrm{O}$ was discontinued and the patient was placed on $100 \% \mathrm{O}_{2}$ at $3 \mathrm{lpm}$ with $8 \%$ sevoflurane. At this point, patients received remifentanil $1 \mu \mathrm{g} \cdot \mathrm{kg}^{-1}$ or remifentanil $2 \mu \mathrm{g} \cdot \mathrm{kg}^{-1}$. Remifentanil was administered as a rapid iv bolus (less than ten seconds). Laryngoscopy with a \#3 Macintosh blade was performed by the primary author (H.J.) one minute later. A 7-mm endotracheal tube with a stylet was used for all patients. Tracheal intubation was categorized as a failure if successful tracheal intubation with end tidal $\mathrm{CO}_{2}$ confirmation was not achieved within two minutes after initiation of laryngoscopy. If conditions for tracheal intubation were poor due to patient movement, inadequate jaw relaxation or inadequate opening of the vocal cords, rocuronium $0.3 \mathrm{mg} \cdot \mathrm{kg}^{-1}$ iv was administered. If the patient coughed for more than $20 \mathrm{sec}$ after tracheal intubation, rocuronium $0.3 \mathrm{mg} \cdot \mathrm{kg}^{-1}$ was administered. After confirmation of successful tracheal intubation, anesthesia was continued using sevoflurane with $1 \mathrm{lpm}$ of $\mathrm{N}_{2} 0$ and $1 \mathrm{lpm}$ of $\mathrm{O}_{2}$.

The primary variables measured were conditions for tracheal intubation. Secondary variables measured included: 1) heart rate, blood pressure, end tidal $\mathrm{CO}_{2}$, end tidal sevoflurane concentration and oxygen saturation, measured every minute; 2 ) time to loss of consciousness; 3 ) degree of muscle rigidity after administration of remifentanil; and 4) time to successful tracheal intubation.

Degree of muscle rigidity after administration of remifentanil was graded as: 0 ) completely relaxed if no resistance to mask ventilation was felt; 1 ) mildly rigid if rigidity was felt by the operator but did not affect manual ventilation; 2) moderately rigid if ventilation was affected but ventilation was still possible; and 3) fully rigid if muscle rigidity made positive pressure ventilation difficult. Conditions for tracheal intubation were assessed using vocal cord opening, jaw relaxation, coughing and patient movement. Vocal cord opening was graded as: 0) open; 1) partially open if they were less than $30^{\circ}$ open; and 2 ) fully closed. Jaw relaxation was graded as: 0 ) fully relaxed if no jaw stiffness was felt; 1) mildly stiff if stiffness was felt but did not affect mouth opening; 2) moderately stiff if there was difficulty in mouth opening but it could be overcome with manual force; 3 ) severely stiff if there was difficulty with mouth opening. Coughing was graded as: 0 ) no cough; 1) mild cough, less than ten seconds; 2) moderate cough; ten to $20 \mathrm{sec}$; and 3 ) severe cough $>20 \mathrm{sec}$. Patient movement was defined as any movement of the arms, legs or thorax.

Time to successful tracheal intubation was defined as the interval between removal of the facemask and 
TABLE I Patient demographics

\begin{tabular}{|c|c|c|}
\hline & $\begin{array}{l}\text { Sevoflurane with } \\
\text { remifentanil } \\
1 \mu g \cdot \mathrm{kg}^{-1} \\
n=28\end{array}$ & $\begin{array}{l}\text { Sevoflurane with } \\
\text { remifentanil } \\
2 \mu \mathrm{g} \cdot \mathrm{kg}^{-1} \\
n=28\end{array}$ \\
\hline ASA physical status & $1(1-1)$ & $1(1-1)$ \\
\hline Age $(\mathrm{yr})$ & $37.6 \pm 8.3$ & $41.2 \pm 11.6$ \\
\hline Weight (kg) & $71.1 \pm 18.3$ & $65.2 \pm 10.4$ \\
\hline Height $(\mathrm{cm})$ & $160.8 \pm 7.1$ & $161.1 \pm 6.0$ \\
\hline Smoker & $6(21 \%)$ & $11(39 \%)$ \\
\hline $\begin{array}{l}\text { End tidal } \mathrm{CO}_{2} 1 \mathrm{~min} \\
\text { before intubation }(\mathrm{mmHg})\end{array}$ & $30(27.5-33.5)$ & $29(26-32)$ \\
\hline $\begin{array}{l}\text { End tidal sevoflurane (\%) } \\
1 \text { min before intubation }\end{array}$ & $4.3 \pm 0.7$ & $4.2 \pm 0.6$ \\
\hline $\begin{array}{l}\text { End tidal sevoflurane (\%) } \\
1 \text { min after intubation }\end{array}$ & $4.5(4.2-5.2)$ & $4.5(4.3-4.8)$ \\
\hline
\end{tabular}

Data expressed as mean \pm standard deviation or median $\left(25-75^{\text {th }}\right.$ percentile) where appropriate. detection of $\mathrm{CO}_{2}$. Optimal intubating conditions were defined as conditions where the jaw was fully relaxed with partially to fully open vocal cords and no coughing at tracheal intubation. Good intubating conditions were defined as conditions where either the jaw was partially relaxed and/or there was mild coughing after tracheal intubation. Marginal intubating conditions were defined as conditions as above but when there was moderate coughing after tracheal intubation, or if the jaw was moderately stiff. Poor intubating conditions were defined as conditions where the jaw was severely stiff, the vocal cords were closed or where there was severe coughing after tracheal intubation. Hypotension was defined as systolic blood pressure $<80 \mathrm{mmHg}$ and hypoxemia was defined as $\mathrm{SpO}_{2}<90 \%$.

Parametric data were analyzed using the Student's t test. Non-parametric data were analyzed using the Mann- Whitney rank sum test. Proportions were analyzed using Fisher's exact test. Hemodynamic

TABLE II Induction and tracheal intubation

\begin{tabular}{|c|c|c|c|}
\hline & & $\begin{array}{l}\text { Sevoflurane with } \\
\text { remifentanil } 1{\mathrm{\mu g} \cdot \mathrm{kg}^{-1}}_{n=28}\end{array}$ & $\begin{array}{l}\text { Sevoflurane with } \\
\text { remifentanil } 2 \mu \mathrm{gg} \cdot \mathrm{kg}^{-1} \\
n=28\end{array}$ \\
\hline \multicolumn{2}{|c|}{ Time to loss of consciousness (sec) } & $44.6 \pm 9.2$ & $43.7 \pm 7.9$ \\
\hline \multirow[t]{4}{*}{ Muscle rigidity } & - none & $13(46 \%)$ & $17(60 \%)$ \\
\hline & -mild & $12(43 \%)$ & $8(29 \%)$ \\
\hline & -moderate & $3(11 \%)$ & $1(4 \%)$ \\
\hline & -severe & $0(0 \%)$ & $2(7 \%)$ \\
\hline \multirow[t]{4}{*}{ Jaw relaxation } & -complete & $24(86 \%)$ & $26(93 \%)$ \\
\hline & -mild stiffness & $4(14 \%)$ & $2(7 \%)$ \\
\hline & -moderate stiffness & 0 & 0 \\
\hline & -severe stiffness & 0 & 0 \\
\hline \multirow[t]{3}{*}{ Vocal cords } & -fully open & $21(75 \%)$ & $22(79 \%)$ \\
\hline & -partially open & $7(25 \%)$ & $6(21 \%)$ \\
\hline & -closed & 0 & 0 \\
\hline \multicolumn{2}{|c|}{$\begin{array}{l}\text { Successful tracheal intubation } \\
\text { Time to successful tracheal }\end{array}$} & $28(100 \%)$ & $28(100 \%)$ \\
\hline \multicolumn{2}{|c|}{$\begin{array}{l}\text { Time to successful tracheal } \\
\text { intubation }(\mathrm{sec})\end{array}$} & $33.9 \pm 9.6$ & $34.7 \pm 11.0$ \\
\hline \multicolumn{4}{|c|}{ Coughing after intubation } \\
\hline \multicolumn{2}{|c|}{ None $(P=0.02)$} & $17(61 \%)^{*}$ & $25(89 \%)^{*}$ \\
\hline \multicolumn{2}{|c|}{ Mild } & $8(29 \%)$ & $3(11 \%)$ \\
\hline \multirow{2}{*}{\multicolumn{2}{|c|}{$\begin{array}{l}\text { Moderate } \\
\text { Severe }\end{array}$}} & $3(11 \%)$ & 0 \\
\hline & & 0 & 0 \\
\hline \multicolumn{4}{|c|}{ Patient movement } \\
\hline \multicolumn{2}{|c|}{ Before intubation } & 0 & 0 \\
\hline \multicolumn{2}{|c|}{ After intubation } & $1(4 \%)$ & 0 \\
\hline \multicolumn{2}{|c|}{$\begin{array}{l}\text { Optimal intubating conditions }(P<0.01) \text { (no cough, jaw relaxed, } \\
\text { no movement) }\end{array}$} & $15(54 \%)^{*}$ & $25(89 \%)^{*}$ \\
\hline \multicolumn{2}{|c|}{$\begin{array}{l}\text { Good intubating conditions (coughing for }<10 \mathrm{sec} \\
\text { or mild jaw stiffness) }\end{array}$} & $10(35 \%)$ & $3(11 \%)$ \\
\hline \multicolumn{2}{|c|}{$\begin{array}{l}\text { Marginal intubating conditions (coughing for }>10 \mathrm{sec} \\
\text { or moderate jaw stiffness) }\end{array}$} & $2(7 \%)$ & $0(0 \%)$ \\
\hline \multicolumn{2}{|c|}{$\begin{array}{l}\text { Poor intubating conditions (coughing }>20 \mathrm{sec} \text {, severe jaw stiffness, } \\
\text { and/or body movement) }\end{array}$} & $l(4 \%)$ & $0(0 \%)$ \\
\hline \multicolumn{2}{|c|}{ Hypotension during induction $(P=0.11)$} & $3(11 \%)$ & $8(29 \%)$ \\
\hline \multicolumn{2}{|c|}{ Lasting for $2-3 \mathrm{~min}$} & $1(4 \%)$ & $2(7 \%)$ \\
\hline Lasting for 1 & & $2(7 \%)$ & $6(22 \%)$ \\
\hline \multicolumn{2}{|c|}{ Hypoxemia during induction $\left(\mathrm{SpO}_{2}<90 \%\right)$} & $1(4 \%)$ & $0(0 \%)$ \\
\hline
\end{tabular}

Data expressed as mean \pm standard deviation where appropriate. 


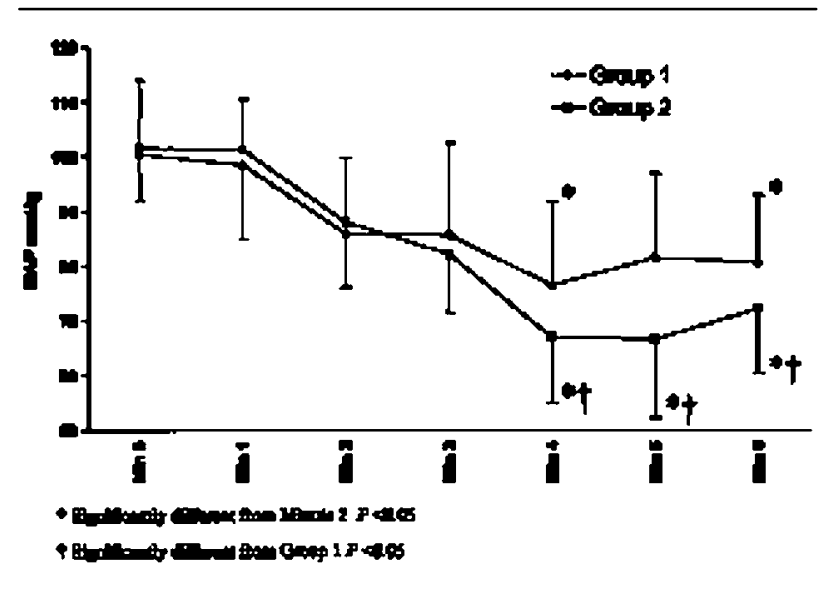

FIGURE 1 Mean arterial blood pressure with standard deviation during the first six minutes of anesthetic induction. Remifentanil was given at two minutes and laryngoscopy was initiated at three minutes.

responses were analyzed using repeated measures ANOVA. SigmaStat 2.0. (SPSS, Chicago, IL, USA) was used for statistical analysis. $P$ value $<0.05$ was considered statistically significant.

\section{Results}

Patient demographics (ASA status, age, weight, height and history of smoking) were similar for both groups (Table I). Induction of anesthesia with sevoflurane/ nitrous oxide was successful in all patients in both groups without any complications. Mean time to loss of consciousness was $45 \mathrm{sec}$ in Group I and $44 \mathrm{sec}$ in Group II (Table II). Following the administration of remifentanil 1 or $2 \mu \mathrm{g} \cdot \mathrm{kg}^{-1}$, the incidence of muscle rigidity or jaw stiffness was similar between the two groups. No patient in either group coughed or moved during laryngoscopy. Mean time to successful tracheal intubation was similar at $34 \mathrm{sec}$ for Group I and $35 \mathrm{sec}$ for Group II. The incidence of post-intubation coughing was higher in Group I at 39\% vs $11 \%$ in Group II ( $P$ $<0.02)$. Optimal intubation conditions were achieved more often in Group II at $89 \%$ vs $54 \%$ in Group I ( $P$ $<0.01)$. However, both groups had a high incidence of good to optimal intubating conditions, with Group I at $89 \%$ and Group II at $100 \%$. The incidence of post-intubation hypotension was $11 \%$ for Group I and 29\% for Group II $(P=0.11)$. The decrease in mean arterial pressure (MAP) was significant compared to baseline $(P$ $<0.05$; Figure 1). However, the decrease in MAP was greater in Group II $(P<0.05)$. Heart rate increased after administration of glycopyrrolate (Figure 2 ). There

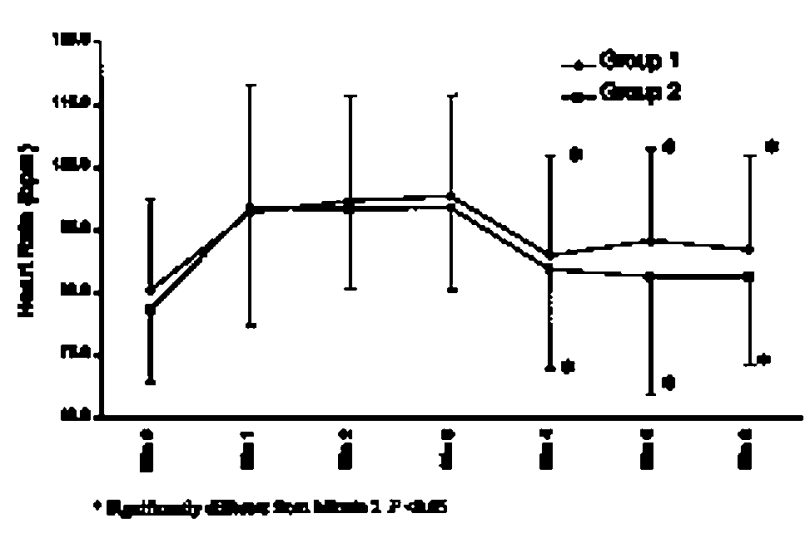

FIGURE 2 Mean heart rate with standard deviation during the first six minutes. Glycopyrrolate was given before initiation of induction. Remifentanil was given at two minutes and tracheal laryngoscopy was initiated at three minutes.

was a significant drop in heart rate following remifentanil administration in both groups $(P<0.05)$. However, no patient developed a heart rate of less than 45 beats. $\mathrm{min}^{-1}$. There were no complications during tracheal intubation. One patient in Group I developed mild hypoxemia $\left(88 \% \mathrm{O}_{2}\right.$ saturation) due to post-intubation coughing but this quickly resolved with increased $\mathrm{FO}_{2}$.

Discussion

The results of this study show that tracheal intubation can be achieved within three minutes of anesthetic induction with sevoflurane and remifentanil. When used with sevoflurane, remifentanil $2 \mu \mathrm{g} \cdot \mathrm{kg}^{-1}$ was associated with better intubating conditions than remifentanil $1 \mu \mathrm{g} \cdot \mathrm{kg}^{-1}$. Both groups, however, had a high proportion of good to optimal conditions for tracheal intubation at $89 \%$ with $1 \mu \mathrm{g} \cdot \mathrm{kg}^{-1}$ and $100 \%$ with 2 $\mu \mathrm{g} \cdot \mathrm{kg}^{-1}$ of remifentanil. These results compare favourably to reported results of propofol/remifentanil tracheal intubation without neuromuscular blocking agents at $35-100 \%{ }^{4-7}$

Potential problems with the use of remifentanil during anesthetic induction include hypoventilation, muscle rigidity and bradycardia. ${ }^{3}$ Muzi et al. studied methods to decrease the time to adequate depth of anesthesia with sevoflurane for tracheal intubation and found that when fentanyl was given before sevoflurane induction, it actually increased time to successful tracheal intubation due to hypoventilation and muscle rigidity. ${ }^{8}$ We administered remifentanil two minutes 
after sevoflurane induction and did not encounter problems with hypoventilation or muscle rigidity. This may be due to the intrinsic muscle relaxant properties of sevoflurane. ${ }^{9}$ Spontaneous ventilation ceased after the administration of remifentanil but positive pressure ventilation with a facemask was possible in all patients. The administration of remifentanil following sevoflurane induction has been associated with severe bradycardia and even asystole. ${ }^{10}$ In the present study, glycopyrrolate was administered as prophylaxis against bradycardia and bradycardia was not encountered. ${ }^{11}$

An advantage of the sevoflurane/remifentanil induction technique is the avoidance of neuromuscular blocking agents. Spontaneous ventilation is preserved until remifentanil is administered. Should airway obstruction arise during induction of anesthesia, induction may be aborted and the patient allowed to awaken. If ventilation difficulties arise after remifentanil is given, its effects may be reversed with naloxone.

Although a sevoflurane/remifentanil induction allows tracheal intubation within three minutes after induction, there may be drawbacks. There was an $11 \%$ incidence of hypotension in the $1 \mu \mathrm{g} \cdot \mathrm{kg}^{-1}$ group and $29 \%$ in the $2 \mu \mathrm{g} \cdot \mathrm{kg}^{-1}$ group. However, hypotension was transient and was easily treated by decreasing the depth of anesthesia. Previously, we have shown that a sevoflurane inhalational induction is associated with a higher incidence of post-operative nausea and vomiting (PONV) when compared to induction with iv propofol. ${ }^{12}$ The induction method in the present study may, possibly, be associated with a similar, high incidence of PONV.

In conclusion, good to optimal conditions for tracheal intubation can be achieved with the use of remifentanil and three minutes of sevoflurane induction. The optimal dose of remifentanil for tracheal intubation in this study was $2 \mu \mathrm{g} \cdot \mathrm{kg}^{-1}$. Sevoflurane/ remifentanil induction and tracheal intubation may be an alternative to tracheal intubation with sevoflurane alone or traditional $i v$ induction agents with neuromuscular blocking agents.

Acknowledgement

We would like to thank Dr. Michael Kolton for his help and guidance with the study protocol and manuscript preparation.

\section{References}

1 Philip BK, Lombard LL, Roaf ER, Drager LR, Calalang I, Philip JH. Comparison of vital capacity induction with sevoflurane to intravenous induction with propofol for adult ambulatory anesthesia. Anesth Analg 1999; 89: 623-7.
2 Muzi M, Robinson BJ, Ebert TJ, O'Brien TJ. Induction of anesthesia and tracheal intubation with sevoflurane in adults. Anesthesiology 1996; 85: 536-43.

3 Michelsen LG, Hug CC The pharmacokinetics of remifentanil. J Clin Anesth 1996; 8: 679-82.

4 Alexander R, Booth J, Olufolabi AJ, El-Moalem HE, Glass PS. Comparison of remifentanil with alfentanil or suxamethonium following propofol anaesthesia for tracheal intubation. Anaesthesia 1999; 54: 1032-6.

5 Alexander R, Olufolabi AJ, Booth J, El-Moalem HE, Glass PS. Dosing study of remifentanil and propofol for tracheal intubation without the use of muscle relaxants. Anaesthesia 1999; 54: 1037-40.

6 Stevens JB, Wheatley L. Tracheal intubation in ambulatory surgery patients: using remifentanil and propofol without muscle relaxants. Anesth Analg 1998; 86: 45-9.

7 Woods AW, Grant S, Harten J, Noble JS, Davidson JA. Tracheal intubating conditions after induction with propofol, remifentanil and lignocaine. Eur $\mathrm{J}$ Anaesthesiol 1998; 15: 714-8.

8 Muzi M, Colinco MD, Robinson BJ, Ebert TJ. The effects of premedication on inhaled induction of anesthesia with sevoflurane. Anesth Analg 1997; 85: 1143-8.

9 Lowry DW, Mirakhur RK, McCarthy GJ, Carroll MT, McCourt KC Neuromuscular effects of rocuronium during sevoflurane, isoflurane, and intravenous anesthesia. Anesth Analg 1998; 87: 936-40.

10 Wang JX, Winship SM, Thomas SD, Gin T, Russell GN. Induction of anaesthesia in patients with coronary artery disease: a comparison between sevofluraneremifentanil and fentanyl-etomidate. Anaesth Intensive Care 1999; 27: 363-8.

11 Hall AP, Thompson JP, Leslie NA, Fox AJ, Kumar N, Rowbotham DJ. Comparison of different doses of remifentanil on the cardiovascular response to laryngoscopy and tracheal intubation. Br J Anaesth 2000; 84: 100-2.

12 Joo HS, Perks WJ. Sevoflurane versus propofol for anesthetic induction: a meta-analysis. Anesth Analg 2000; 91: 213-9. 